\title{
PROPHYLACTIC INTRAMUSCULAR EPHEDRINE BEFORE EPIDURAL ANAESTHESIA FOR CAESAREAN SECTION: EFFICACY AND ACTIONS ON THE FOETUS AND NEWBORN
}

\author{
Stephen H. Rolbin, A.F.D. Cole, Ernest M. Hew, A. Pollard and Susan Virgint
}

\begin{abstract}
The authors studied the effectiveness of ephedrine given intramuscularly before epidural anaesthesia with bupivacaine 0.5 per cent in three groups of patients undergoing elective caesarean section. The patients received intramuscular saline as a placebo, ephedrine $25 \mathrm{mg}$ or ephedrine $50 \mathrm{mg}, 15$ to 30 minutes before anaesthesia. The incidence of hypotension was 8 to 12 per cent in all three groups.

Prophylactic intramuscular ephedrine did not lower the incidence of hypotension significantly. Intramuscular ephedrinc $50 \mathrm{mg}$ caused a persistent hypertension in eight out of 12 patients and was associated with an increase in umbilical artery $\left[\mathrm{H}^{+}\right]$(decrease in $\mathrm{pH}$ ). No differences were observed in other indices of neonatal well-being. The prophylactic use of intramuscular ephedrine before epidural anaesthesia for caesarean section is not recommended.
\end{abstract}

Key Words: ANAesthesia, obstetrical; Anaesthetic Techniques, epidural; CoMPLICATIONS, hypotension, ephedrine prophylaxis.

REGIONAL ANAESTHESIA at delivery is safest for mother and infant, but maternal hypotension is a common complication. ${ }^{1-4}$ Maternal hypotension is less common during vaginal delivery ${ }^{5}$ than during caesarean sections, where higher levels of anaesthesia are required. ${ }^{6}$

The measures often used to prevent hypotension with epidural anaesthesia include left uterine displacement, acute intravenous hydration and the use of vasopressors.

Left uterine displacement decreases caval compression and lowers the incidence of hypotension. ${ }^{7.8,9}$ When acute intravenous hydration is

Stephen H. Rolbin, M.D.C.M., F.R.C.P.(C), CoDirector, Obstetrical Anaesthesia, Assistant Professor of Anaesthesia; A.F.D. Cole, M.D., F.R.C.P.(C), Co-Director, Obstetrical Anaesthesia, Assistant Professor of Anaesthesia; Emest M. Hew, M.D., F.R.C.P.(C), F.F.A.R.C.S.(I), Co-Director of Intensive Care Unit, Associate Professor of Anacsthesia A. Pollard, M.A., M.B., B.Chir, M.R.C.P. F.R.C.Path., Associate Professor, Department of Clinical Biochemistry; Susan Virgint, R.R.T., Research Technologist; Departments of Anaesthesia and Clinical Biochemistry, Mount Sinai Hospital, and The University of Toronto, with the assistance of the Statistical Consulting Service, University of Toronto and Shirley Siu, Research Technologist, Department of Clinical Biochemistry.

Reprint requests to: Dr. S. Rolbin, Department of Anaesthesia, Mount Sinai Hospital, 600 University Avenue, Toronto, Ontario, M5G IX5.

Can. Anaesth. Soc. J., vol. 29, no. 2, March 1982 combined with lateral tilt, the incidence is further decreased, ${ }^{8,10,11}$ but because it is still significant, the prophylactic intramuscular use of vasopressors has been recommended. ${ }^{12}$

After administration of epidural anaesthesia for caesarean section, we proposed to document the incidence of hypotension with the combined use of lateral tilt and intravenous hydration, and to assess the efficacy of prophylactic intramuscular ephedrine in reducing the incidence of maternal hypotension and its effects on the foetus and newbom.

\section{METHODS}

The Human Experimentation Committee of the University of Toronto approved the protocol and all parients gave informed consent. Sixtytwo healthy parturients, with vertex presentation undergoing elective caesarean section at term, without foetal or maternal complications, were studied. All patients were positioned with 15 to 30 degrees of left uterine displacement and acutely hydrated with one litre of balanced electrolyte solution with dextrose before epidura anaesthesia. The patients were assigned randomly to one of three groups: Group I (25 patients) saline placebo; Group II (25 patients) intramuscular ephedrine $25 \mathrm{mg}$; Group III (12 
patients) intramuscular ephedrine $50 \mathrm{mg} ; 15$ to 30 minutes before epidural anaesthesia. A single lumbar epidural injection of 27 to $30 \mathrm{ml}$ of bupivacaine 0.5 per cent was administered at the L3,4 or L2,3 interspace. Maternal blood pressure (measured by the Riva-Rocci method), and heart rate were recorded at one minute intervals up to the delivery of the baby and at five minute intervals for the duration of anaesthesia by an observer who did not know to which group the patient had been allocated. Maternal radial artery puncture was done at the time of birth to obtain blood for determination of blood gases, acid-base status and plasma bupivacaine levels. Whole blood bupivacaine levels were determined using a modified gas-liquid chromatographic method. ${ }^{13}$

The foetus was assessed by Apgar scores at one and five minutes of age. At birth, umbilical arterial and venous blood gases, acid-base status and bupivacaine levels were measured. Newborn blood pressure and heart rate were assessed at 15 and heart rate alone at 60 minutes of age. Newborn blood pressure was measured by a Doppler ultrasonic transducer (Artiosonde(B) 1010 by Roche). A neurobehavioural examination was done as described by Scanlon at four and 24 hours of age by a trained observer who did not know to which group the patient had been allocated.

If maternal hypotension (systolic pressure less than $13.3 \mathrm{kPa}(100 \mathrm{mmHg})$ or 70 per cent of pre-operative pressure) occurred it was treated promptly by placing the patient in the head down position, rapid fluid infusion and further displacement of the uterus. If hypotension failed to respond to these measures it was treated with small doses of ephedrine (5-10 $\mathrm{mg}$ ) intravenously as necessary. If intravenous ephedrine was given then subsequent observations in time were removed from analysis.

\section{RESULTS}

The three groups were comparable for height and weight, parity, acute intravenous hydration (which averaged $740 \mathrm{ml}$ before epidural and $1350 \mathrm{ml}$ before delivery) duration of anaesthesia prepartum and uterine incision time as analyzed by Multivariate Analysis of Variance ${ }^{14}$ (MANOVA) (Table I). The maximum height of blockade, and presumably the degree of vasodilation, was comparable in all three groups assessed, and ranged from the second to the sixth thoracic dermatome.

\section{(a) The Mother}

The incidence of hypotension was eight to 12 per cent in all three groups. By Contingency Table Analysis there is no significant change in the incidence of hypotension with the use of ephedrine $(0.8<p<0.9)$ (Table II). Only three patients failed to respond to further hydration and increased uterine displacement. One patient was in group I and two were in group II, and they responded to supplemental intravenous doses of ephedrine 5-10 mg. No overshoot hypertension was associated with the intravenous use of ephedrine. Maternal blood gas values were assessed by MANOVA and found to be similar in all three groups. The mean values were $\left[\mathrm{H}^{+}\right]$a $39.81 \pm 0.4 \mathrm{nmol} / 1(\mathrm{pH} 7.40 \pm 0.004), \mathrm{PCO}_{2}$ $3.83 \pm 0.06 \mathrm{kPa}\left(28.8 \pm 0.4\right.$ torr) $\mathrm{Po}_{2} 24.87 \pm$ $1.08 \mathrm{kPa}(187 \pm 8.1$ torr) and bicarbonate 17.7 $+0.3 \mathrm{mmol} / \mathrm{l}$. Bupivacaine levels averaged 0.93 $\pm 0.08 \mu \mathrm{g} / \mathrm{ml}$ and were similar in all three groups as assessed by Analysis of Variance (ANOVA).

During the conduct of the study we noted an unacceptably high incidence of hypertension which prompted preliminary analysis of the data. Hypertension was associated with prophylactic use of ephedrine $50 \mathrm{mg}$ (group III) and because of this, only 12 patients were given this dose. The maximum systolic blood pressure prepartum rose to more than 30 per cent above preanaesthetic values in 75 per cent of patients in group III. This is in contrast to 16 per cent of patients who received saline only (Figure 1). Three of the patients in group III had a maximum systolic pressure increase of more than 60 per cent. The number of patients with significant increases in systolic blood pressure as assessed by Contingency Table Analysis ${ }^{14}$ was significant $(0.001<\mathrm{p}<0.01)$

Maternal blood pressure and heart rate were measured on admission to hospital and immediately before anaesthesia, and were not found to be significantly different. The changes in blood pressure were assessed, three time intervals at a time, by MANOVA to compare all three groups of patients and by Hotelling's I Squared Statistic ${ }^{14}$ to compare the control group with patients receiving ephedrine $25 \mathrm{mg}$ (Figure 2 and Table III). Ephedrine $50 \mathrm{mg}$ increased mean maternal systolic blood pressure for at least 60 minutes and this is significant to the 0.001 level. Matemal systolic blood pressure was elevated significantly between 40 to 60 minutes in those patients who received ephedrine $25 \mathrm{mg}$. Diastolic blood pressure was 
TABLE I

Clinical information* (Mean \pm SE)

\begin{tabular}{|c|c|c|c|}
\hline & \multicolumn{3}{|c|}{ Ephedrine Dose (mg) } \\
\hline & 0 & 25 & 50 \\
\hline Height (inches) & $63 \pm 0.5$ & $63 \pm 0.6$ & $64 \pm 0.7$ \\
\hline Weight (pounds) & $158 \pm 4.6$ & $151 \pm 4.5$ & $162 \pm 7.4$ \\
\hline \multicolumn{4}{|l|}{ Prehydration: (ML) } \\
\hline Before Epidural & $698 \pm 65$ & $700 \pm 47$ & $918 \pm 131$ \\
\hline Before Delivery & $1318 \pm 82$ & $1287 \pm 90$ & $1547 \pm 117$ \\
\hline \multicolumn{4}{|l|}{ Duration of Anaesthesia } \\
\hline Prepartum (min) & $20.5 \pm 0.76$ & $22.3 \pm 0.69$ & $23.8 \pm 1.48$ \\
\hline Skin Incision to Delivery ( $\mathrm{min}$ ) & $8.6 \pm 0.53$ & $10.6 \pm 0.71$ & $11.4 \pm 1.32$ \\
\hline \multicolumn{4}{|l|}{ Uterine Incision } \\
\hline to Delivery Time (sec) & $83 \pm 9.3$ & $97 \pm 7.0$ & $119 \pm 19.3$ \\
\hline
\end{tabular}

*No significant differences by Multivariate Analysis of Variance

TABLE II

ThE INCIDENCE OF HyPOTENSION BEFORE DELIVERY

\begin{tabular}{cccc}
\hline \hline $\begin{array}{c}\text { Ephedrine } \\
\text { Dose }(\mathrm{mg})\end{array}$ & $\begin{array}{c}\text { Number of } \\
\text { Patients }\end{array}$ & $\begin{array}{c}\text { Number with } \\
\text { Hypotension }\end{array}$ & $\begin{array}{c}\text { Percentage } \\
\text { with } \\
\text { Hypotension }\end{array}$ \\
\hline 0 & 25 & 3 & 12 \\
25 & 25 & 3 & 12 \\
50 & 12 & 1 & 8 \\
\hline
\end{tabular}

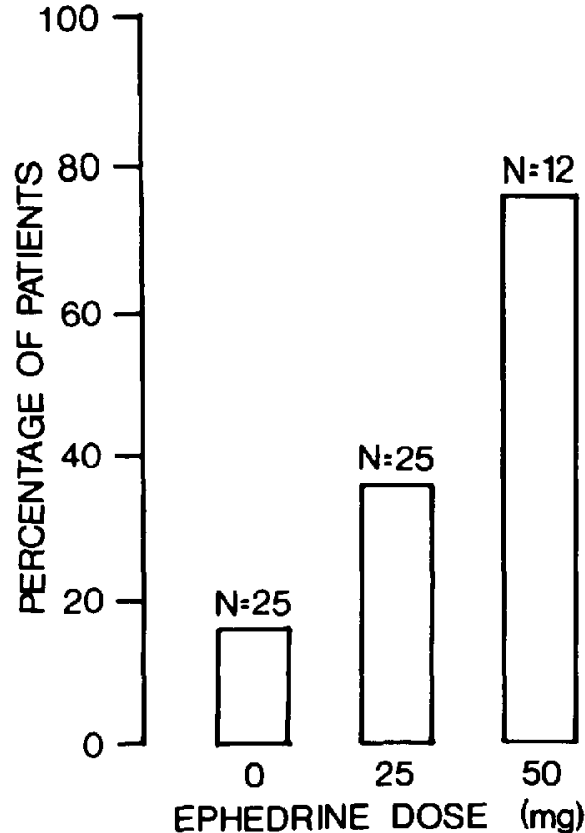

FIGURE 1 The percentage of patients with a maximum systolic blood pressure increase of more than 30 per cent after ephedrine prophylaxis. elevated significantly between $25-50$ minutes only in those receiving ephedrine $50 \mathrm{mg}$, while heart rate showed a dose related increase from 15 to 60 minutes after intramuscular administration of ephedrine.

\section{(b) Foetus and Newborn}

Two infants whose mothers received saline and two whose mothers received ephedrine $50 \mathrm{mg}$ had one minute Apgar scores of six or less. There was no obvious cause. By five minutes of age all babies had Apgar scores of seven or more. No difference was observed in newborn blood pressure and heart rate at 15 minutes and heart rate alone at 60 minutes. Umbilical venous $\left[\mathrm{H}^{+}\right] 48.98 \pm 1.13 \mathrm{nmol} / 1(\mathrm{pH}$ $7.31 \pm 0.01), \mathrm{PCO}_{2} 5.45 \pm 0.11 \mathrm{kPa}(41.2 \pm$ 0.8 torr), $\mathrm{PO}_{2} 4.02 \pm 0.13 \mathrm{kPa}(30.2 \pm 1.0$ torr) and bicarbonate $20.3 \pm 0.3 \mathrm{mmol} / \mathrm{l}$. These values were similar in all three groups.

The infants whose mothers received placebo or ephedrine $25 \mathrm{mg}$ had an umbilical artery [ $\left.\mathrm{H}^{+}\right]$ $54.95 \pm 1.26 \mathrm{nmol} / 1(\mathrm{pH} 7.26 \pm 0.01), \mathrm{PCO}_{2}$ $6.74 \pm 1.8 \mathrm{kPa}(50.7 \pm 1.3$ torr $), \mathrm{Po}_{2} 2.38 \pm$ $0.17 \mathrm{kPa}(17.9 \pm 1.25 \mathrm{torr})$ and bicarbonate $22.0 \pm 0.54 \mathrm{mmol} / \mathrm{l}$. The umbilical artery $\left[\mathrm{H}^{+}\right]$ of $66.07 \pm 2.26 \mathrm{nmol} / \mathrm{l}(\mathrm{pH} 7.18 \pm 0.02)$ was significantly higher ( $\mathrm{pH}$ lower) in the group re- 


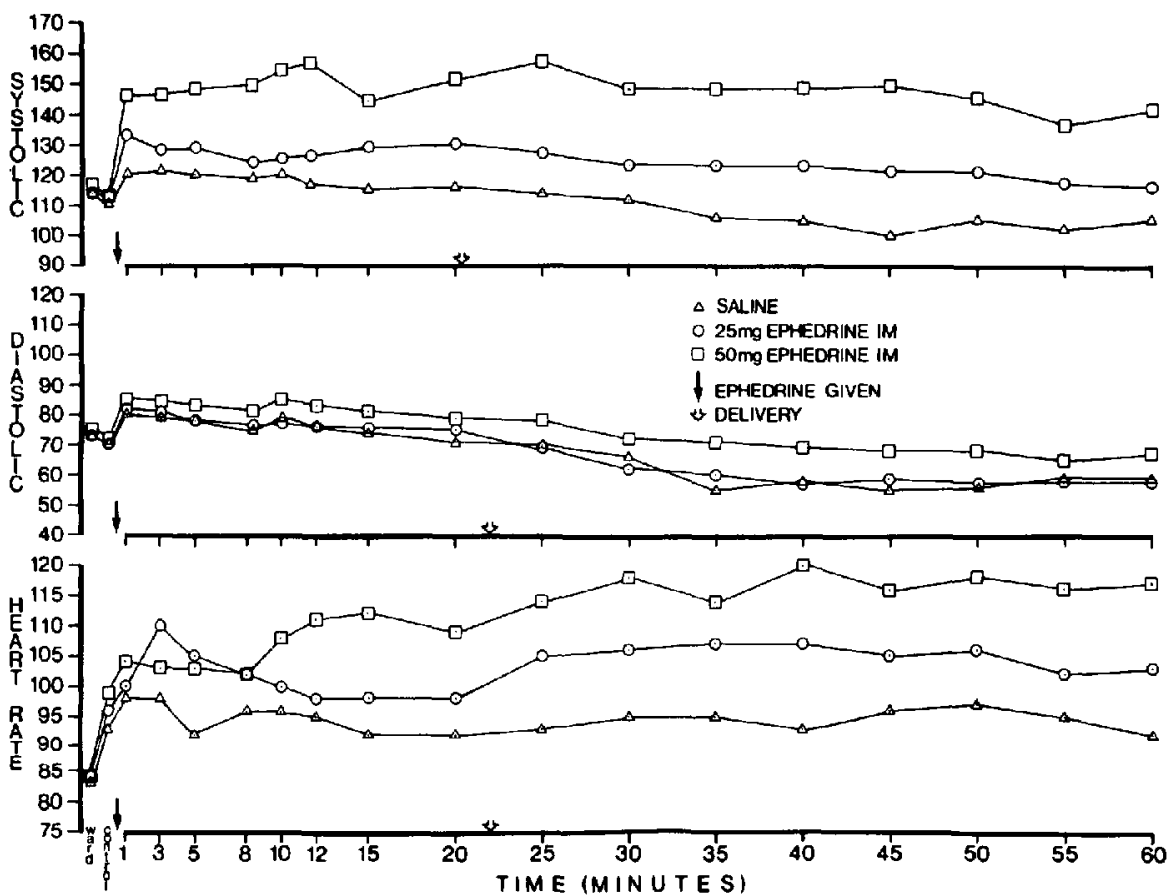

FIGURE 2 Effect of ephedrine prophylaxis on mean maternal systolic blood pressure, diastolic blood pressure and heart rate. The levels of significance are shown in Table III.

TABLE III

Maternal HaEmodynamic Data

(Difference Found at the Following Significance Levels)

\begin{tabular}{|c|c|c|c|c|c|c|}
\hline \multirow[b]{2}{*}{$\begin{array}{l}\text { Time Intervals } \\
\text { Minutes }\end{array}$} & \multicolumn{2}{|c|}{$\begin{array}{c}\text { Systolic B.P. } \\
\text { Comparing }\end{array}$} & \multicolumn{2}{|c|}{$\begin{array}{c}\text { Diastolic B.P. } \\
\text { Comparing }\end{array}$} & \multicolumn{2}{|c|}{$\begin{array}{l}\text { Heart Rate } \\
\text { Comparing }\end{array}$} \\
\hline & $\underset{\text { Groups* }}{\text { All }}$ & $\begin{array}{l}\text { Groups } \\
\text { I \& II } \dagger\end{array}$ & $\begin{array}{l}\text { All } \\
\text { Groups* }\end{array}$ & $\begin{array}{l}\text { Groups } \\
\text { I \& I† }\end{array}$ & $\begin{array}{c}\text { All } \\
\text { Groups* }\end{array}$ & $\begin{array}{l}\text { Groups } \\
\text { I \& II } †\end{array}$ \\
\hline Control & 0.70 & - & 0.91 & - & 0.70 & - \\
\hline $1,3,5$ & 0.001 & 0.025 & 0.80 & 0.10 & 0.75 & 0.10 \\
\hline $8,10,12$ & 0.001 & 0.15 & 0.50 & 0.10 & 0.11 & 0.10 \\
\hline $15,20,25$ & 0.001 & 0.05 & 0.20 & 0.10 & 0.001 & 0.001 \\
\hline $25,30,35$ & 0.001 & 0.10 & 0.05 & 0.10 & 0.001 & 0.025 \\
\hline $40,45,50$ & 0.001 & 0.005 & 0.02 & 0.10 & 0.001 & 0.001 \\
\hline $50,55,60$ & 0.001 & 0.025 & 0.30 & 0.10 & 0.005 & 0.025 \\
\hline
\end{tabular}

*Multivariate analysis of variance.

†Hotelling's T squared statistic.

ceiving ephedrine $50 \mathrm{mg}(\mathrm{p}<0.005$; MANOVA and simultaneous confidence intervals ${ }^{14}$ ).

Each group had equivalent levels of bupivacaine in the umbilical artery $(0.247 \pm 0.030$ $\mu \mathrm{g} / \mathrm{ml})$ and umbilical vein $(0.155 \pm 0.019$ $\mu \mathrm{g} / \mathrm{ml})$.

Neurobehavioural assessments at two to four hours of age and on the second day were compared by Contingency Table Analysis. Ephedrine had no effect on neurobehavioural assessments (Table IV).

\section{Discussion}

Intravenous ephedrine is accepted as the treatment of choice for maternal hypotension in 
TABLE IV

Percentage of Neonates with High Scores on the Scanlon Neurobehavioural Examination

\begin{tabular}{|c|c|c|c|c|c|c|}
\hline & \multicolumn{2}{|c|}{$0 \mathrm{mg}$} & \multicolumn{2}{|c|}{$25 \mathrm{mg}$} & \multicolumn{2}{|c|}{$50 \mathrm{mg}$} \\
\hline & Day 1 & Day 2 & Day 1 & Day 2 & Day 1 & Day 2 \\
\hline Response to Pinprick & 78 & 81 & 59 & 86 & 66 & 81 \\
\hline Habituation Present & 92 & 96 & 96 & 100 & 100 & 90 \\
\hline Pull to sitting & 34 & 81 & 50 & 86 & 36 & 72 \\
\hline Arm Recoil & 78 & 81 & 72 & 68 & 58 & 54 \\
\hline Truncal Tone & 43 & 72 & 77 & 81 & 50 & 81 \\
\hline General Body Tone & 78 & 100 & 77 & 95 & 75 & 81 \\
\hline Rooting & 39 & 68 & 54 & 59 & 25 & 72 \\
\hline Sucking & 56 & 63 & 63 & 72 & 66 & 81 \\
\hline Moro Response & 78 & 50 & 59 & 71 & 66 & 63 \\
\hline Habituation Present & 96 & 100 & 100 & 96 & 100 & 100 \\
\hline Habituation to Light in Eyes & 92 & 96 & 96 & 96 & 91 & 90 \\
\hline Response to Sound & 39 & 54 & 45 & 59 & 25 & 71 \\
\hline Placing & 90 & 95 & 77 & 95 & 83 & 100 \\
\hline Alertness & 69 & 81 & 72 & 90 & 66 & 90 \\
\hline General Assessment & 73 & 95 & 90 & 86 & 75 & 72 \\
\hline
\end{tabular}

obstetrical anaesthesia. The prophylactic use of ephedrine has been advocated ${ }^{12}$ and we wished to assess its efficacy and safety.

Our study records the incidence of hypotension during caesarean section under epidural anaesthesia and is the first study to compare the efficacy of prophylactic intramuscular ephedrine with a control group. The incidence of maternal hypotension during epidural anaesthesia with bupivacaine was 12 per cent when using acute intravenous hydration and left uterine displacement. Prophylactic intramuscular ephedrine 25 or $50 \mathrm{mg}$ did not significantly lower the incidence of hypotension. In addition, the prophylactic intramuscular administration of ephedrine $50 \mathrm{mg}$ was associated with an unacceptably high incidence ( 75 per cent) of persistent maternal hypertension and a detectable change in umbilical artery acid-base status. Ward, et al. ${ }^{15}$ did not demonstrate any adverse effect of intramuscular ephedrine, 25 or $50 \mathrm{mg}$, given prophylatically before epidural anaesthesia for caesarean section. They studied maternal blood pressure or umbilical vessel acid-base values. We have no explanation for the difference in our results. The amount of intravenous hydration and uterine incision to delivery times were not significantly different between our three groups and should not have influenced the results.

The high percentage of neonates with high scores on neurobehavioural assessment is expected, since all the patients were having elective caesarean sections with bupivacaine analgesia.
The prophylactic intramuscular use of ephedrine before epidural anaesthesia is not recommended. Oxygen, hydration, further lateral positioning and, if necessary, intravenous ephedrine remain the current treatment of acute hypotension in obstetrics.

\section{REFERENCES}

1. Fox, G.S., SMith, J.B., NAMBa, Y., et al. Anesthesia for cesarean section: Further studies. Am. J. Obstet. Gynecol., 133: 15-19 (1979).

2. Palahniuk, R.J., Scatliff, J., Biehl, D., et al. Maternal and Neonatal effects of methoxyflurane, nitrous oxide and lumbar epidural anaesthesia for caesarean section. Can. Anaesth. Soc. J., 24: 586-596 (1977).

3. James, F.M. III, Crawford, J.S., Hopkinson, $R$, et al. A comparison of general anaesthesia and lumbar epidural for elective cesarean section. Anesth. Analg. (Cleve.) 56: $228-235$ (1977).

4. Downing, J.W., Houlton, P.C. \& Barclay, A. Extradual analgesia for caesarean section: $A$ comparison with general anaesthesia. Br. J. Anaesth., 51: 367-373 (1979).

5. Kennedy, R.L., Friedman, D.L., Katcha, D.M., et al. Hypotension during obstetrical anaesthesia. Anesthesiology 20: 153-155 (1959).

6. Wollman, S.B. \& Marx, G.F. Acute hydration for prevention of hypotension of spinal anesthesia in parturients. Anesthesiology 29: 374-380 (1968).

7. Crawford, J.S., Burton, M. \& Davies, P. Time and lateral tilt at cesarean section. Br. J. Anaesth. 44: 477-484 (1972).

8. Clark, R.B. Thompson, D.S. \& Thompson, C.H. Prevention of spinal hypotension associated with cesarean section. Anesthesiology 45: 670674 (1976).

9. Datta, S., Alper, M.H. Osthelmer, G.W, el 
al. Effects of maternal position on epidural anesthesia for cesarean section acid-base status and bupivacaine concentrations at delivery. Anesthesiology 50: 205-209 (1979).

10. Marx, G.F., Cosmi, E.V. \& Wollman, S.B. Biochemical status and clinical condition of mother and infant at cesarean section. Anesth. Analg. (Cleve.) 48: 986-993 (1969).

11. Gutsche, B.B. Prophylactic ephedrine preceding spinal analgesia for cesarean section. Anesthesiology 45: 462-465 (1976)

12. Shnider, S.M. \& Tevinson, G. Anesthesia for cesarean section. Anesthesia for Obstetrics. Edited by Sol M. Shnider and G. Levinson, Williams and Wilkins, Baltimore: 254-278 (1979).

13. Zylber-Katz, E., Granit, L. \& Levy, M. Gas-Liquid Chromatographic Determination of Bupivacaine and Lidocaine in Plasma. Clin. Chem. 24: 1573-1575 (1978)

14. Multivariate Statistical Methods. Morrison, D.F. (ed) McGraw-Hill Book Company, Toronto.

15. Ward, M.G., HugheS, S.C., ShNider, S.M. $e t$ al. Anesthesiology (Suppl.), 51: S307 (1979).

Résumé

Les auteurs ont étudié l'efficacité de l'éphédrine administrée par la voie intramusculaire avant l'épidurale à la bupivacaïne 0.5 pour cent sur trois groupes de patientes subissant une césarienne. Le premier groupe a reçu un placebo constitué de soluté physiologique intramusculaire, le deuxième éphédrine $25 \mathrm{mg}$ et le troisième éphédrine $50 \mathrm{mg}$ administrés 15 a 30 minutes avant l'anesthésie. L'incidence d'hypotension a été de 8 à 12 pour cent dans les trois groupes.

L'éphédrine administrée prophylactiquement par la voie intramusculaire n'a pas diminué l'incidence d'hypotension de façon significative. A la dose de $50 \mathrm{mg}$ l'éphédrine a causé une hypertension persistente chez 8 des 12 patientes du groupe et s'est accompagnée d'une baisse du $\mathrm{pH}$ dans l'artère ombilicale. Aucune autre différence dans les critères d'évaluation néonatale n'a été notée. L'usage prophylactique d'éphédrine par la voie intramusculaire avant l'anesthésie épidurale pour la césarienne n'est donc pas recommandé. 